\title{
High incidence of upper-extremity deep vein thrombosis with dual-lumen venovenous extracorporeal membrane oxygenation
}

\author{
Alexis E. Shafii, MD, Chase R. Brown, BS, Sudish C. Murthy, MD, PhD, and David P. Mason, MD, \\ Cleveland, Ohio
}

\begin{abstract}
Venovenous extracorporeal membrane oxygenation (ECMO) has emerged as an important intervention for patients with acute respiratory failure, as well as as a bridge to lung transplantation for end-stage lung disease. ${ }^{1,2} \mathrm{~A}$ recently introduced bicaval, dual-lumen cannula appears to be a promising technologic advancement for venovenous ECMO support. Introduced percutaneously through the right internal jugular or left subclavian vein, the Avalon Elite cannula (Avalon Laboratories, Rancho Dominguez, Calif) selectively drains venous blood from the inferior and superior venae cavae and infuses oxygenated blood directly into the right atrium. Advantages of this cannula include a single insertion and upper body placement, which can allow ambulation to maintain patient conditioning. ${ }^{3}$ Although the cannula is available in multiple sizes (23-31F), clinical experience has shown that larger cannula sizes are required to generate adequate flow for respiratory support in adults $(>4.0 \mathrm{~L} / \mathrm{min})$. Larger cannulas used for extended durations, however, probably predispose the patient toward upper-extremity deep venous thrombosis (DVT). We evaluated the incidence and subsequent clinical implications of upper extremity DVT in patients who were supported with venovenous ECMO by means of the Avalon dual-lumen cannula.
\end{abstract}

\section{MATERIALS AND METHODS}

Between July 2009 and February 2012, we identified, from an institutional review board-approved ECMO database, 10 patients who were placed on venovenous ECMO with the Avalon dual-lumen cannula. ECMO was initiated as a bridge to lung transplantation in 9 cases and for adult respiratory distress syndrome in 1 case. Cannula placements were all performed in the operating room under fluoroscopic and echocardiographic guidance. The right internal jugular vein was cannulated in 4 patients, and the left subclavian vein was used in 6 patients (Table 1). System components included a Quadrox D oxygenator with a Jostra RotaFlow centrifugal pump and heparin-bonded Bioline tubing (Maquet Inc, Wayne, NJ). Systemic anticoagulation was initiated with an intravenous heparin bolus and infusion at the time of ECMO insertion and titrated for a goal partial thromboplastin time of 45 to 65 seconds. ECMO separations were performed through a limited cutdown incision, and hemostasis of the

From the Department of Thoracic and Cardiovascular Surgery, Heart and Vascular Institute, Cleveland Clinic, Cleveland, Ohio.

Disclosures: Authors have nothing to disclose with regard to commercial support.

Received for publication April 20, 2012; revisions received May 10, 2012; accepted for publication June 12, 2012; available ahead of print July 12, 2012

Address for reprints: David P. Mason, MD, Department of Thoracic and Cardiovascular Surgery, J4-1, Cleveland Clinic, 9500 Euclid Ave, Cleveland, OH 44195

(E-mail: masond2@ccf.org).

J Thorac Cardiovasc Surg 2012;144:988-9

$0022-5223 / \$ 36.00$

Copyright (c) 2012 by The American Association for Thoracic Surgery

http://dx.doi.org/10.1016/j.jtcvs.2012.06.028 cannulation site was achieved with a purse-string suture encompassing the overlying soft tissue. All patients underwent upper-extremity surveillance duplex ultrasonography.

\section{RESULTS}

Eight patients $(80 \%)$ had acute upper-extremity DVT while supported through the Avalon cannula. Median time of ECMO support was 15 days (range, 3-40 days). DVT localization appeared to be related to the anatomic side of cannulation. Ipsilateral arm swelling or thrombophlebitis was observed in all 8 patients with ultrasonographically confirmed upper-extremity DVTs. Five patients were managed with systemic anticoagulation with heparin (or warfarin after decannulation), whereas 3 patients did not receive anticoagulation because of relative contraindications ( 2 because of postoperative or posttransplant coagulopathy and 1 because of gastrointestinal bleeding). Complete or partial resolution of clot was noted in all patients (6 complete and 2 partial) at a median of 23 days (range, 10-59 days) from initial detection (Table 1). During this follow-up period, no clinically apparent pulmonary embolisms occurred. Two patients underwent contrast-enhanced computed tomographic scans after DVT detection; both were without evidence of subclinical pulmonary embolism.

\section{DISCUSSION}

Upper-extremity DVTs have largely been regarded as benign and self-limited, with low risk of pulmonary embolism. A large series of upper-extremity DVTs demonstrated a low prevalence of pulmonary embolism (3\%), as opposed to a much higher prevalence $(16 \%)$ with lower-extremity DVTs. ${ }^{4}$ In the setting of venovenous ECMO to treat respiratory failure, however, large, central, upper-extremity DVTs may predispose toward thromboembolism formation in already compromised patients. We have previously noted a high prevalence of DVTs $(22 \%)$ with peripheral ECMO in patients supported after lung transplantation, although the clinical courses of these DVTs (and their long-term sequelae) have not been well defined. ${ }^{5}$ In this report, we have documented a remarkably high prevalence of acute upper-extremity DVTs with the use of the Avalon cannula, both ipsilateral and contralateral to the site of insertion. This is presumably due to partial obstruction of upper-body venous return and alteration in flow dynamics induced by the large cannula positioned in the superior vena cava. Although DVT formation might perhaps have been reduced by higher heparin dosages (partial thromboplastin time 60-80 seconds), such as is used with venoarterial ECMO, 
TABLE 1. Patient characteristics

\begin{tabular}{|c|c|c|c|c|c|c|c|c|}
\hline Case & Age (y) & Sex & $\begin{array}{c}\text { ECMO } \\
\text { duration (d) }\end{array}$ & $\begin{array}{c}\text { Cannula } \\
\text { size }(F)\end{array}$ & $\begin{array}{c}\text { Cannulation } \\
\text { site }\end{array}$ & $\begin{array}{c}\text { DVT } \\
\text { location }\end{array}$ & $\begin{array}{c}\text { DVT } \\
\text { resorption }\end{array}$ & $\begin{array}{c}\text { DVT } \\
\text { treatment }\end{array}$ \\
\hline 1 & 28 & $\mathrm{~F}$ & 18 & 31 & Left subclavian & L-axillary & Complete & Yes \\
\hline 2 & 53 & $\mathrm{~F}$ & 40 & 27 & Left subclavian & $\begin{array}{l}\text { Left internal jugular, right } \\
\text { subclavian, and right axillary }\end{array}$ & Partial & No \\
\hline 3 & 61 & $\mathrm{~F}$ & 3 & 31 & Left subclavian & Left internal jugular & Complete & Yes \\
\hline 4 & 55 & $\mathrm{~F}$ & 12 & 31 & Left subclavian & $\begin{array}{l}\text { Right internal jugular, right } \\
\text { subclavian, and right axillary }\end{array}$ & Partial & No \\
\hline 5 & 59 & M & 3 & 31 & Right internal jugular & Right internal jugular & Complete & Yes \\
\hline 6 & 56 & $\mathrm{~F}$ & 5 & 27 & Right internal jugular & Right internal jugular & Complete & No \\
\hline 7 & 48 & $\mathrm{~F}$ & 15 & 27 & Right internal jugular & Right internal jugular & Complete & Yes \\
\hline 8 & 33 & $\mathrm{~F}$ & 15 & 23 & Right internal jugular & Left brachial & Complete & Yes \\
\hline 9 & 51 & $\mathrm{M}$ & 19 & 31 & Left subclavian & No DVT & NA & NA \\
\hline 10 & 58 & M & 21 & 31 & Left subclavian & No DVT & NA & NA \\
\hline
\end{tabular}

$D V T$, Deep venous thrombosis; $E C M O$, extracorporeal membrane oxygenation; $F$, female; $M$, male; $N A$, not applicable.

we have used a generally accepted anticoagulation regimen for venovenous ECMO. Fortunately, no clinically evident pulmonary embolisms occurred, perhaps attributable to our aggressive DVT treatment strategy. Of note, 2 patients left untreated because of risk factors for bleeding demonstrated incomplete DVT resolution, highlighting the importance of anticoagulation and the need for continued duplex surveillance.

In conclusion, the Avalon cannula is an important innovation that demonstrates promise for venovenous ECMO in respiratory support. Clinicians should, however, be aware of the high risk of DVT associated with its use and remain vigilant with respect to treatment and radiologic follow-up.

\section{References}

1. Schmid C, Philipp A, Hilker M, Rupprecht L, Arlt M, Keyser A, et al. Venovenous extracorporeal membrane oxygenation for acute lung failure in adults. J Heart Lung Transplant. 2012;31:9-15.

2. Hämmäinen P, Schersten H, Lemström K, Riise GC, Kukkonen S, Swärd K, et al. Usefulness of extracorporeal membrane oxygenation as a bridge to lung transplantation: a descriptive study. J Heart Lung Transplant. 2011;30: $103-7$.

3. Garcia JP, Kon ZN, Evans C, Wu Z, Iacono AT, McCormick B, et al. Ambulatory veno-venous extracorporeal membrane oxygenation: innovation and pitfalls. $J$ Thorac Cardiovasc Surg. 2011;142:755-61.

4. Joffee HV, Kucher N, Tapson VF, Goldhaber SZ, Deep Vein Thrombosis (DVT) FREE Steering Committee. Upper-extremity deep vein thrombosis: a prospective registry of 592 patients. Circulation. 2004;110:1605-11.

5. Mason DP, Boffa DJ, Murthy SC, Gildea TR, Budev MM, Mehta AC, et al. Extended use of extracorporeal membrane oxygenation after lung transplantation. J Thorac Cardiovasc Surg. 2006;132:954-60. 